\title{
Foreword: knowing what to know, what to do and how to do it in the Anthropocene
}

\section{Noel Castree}

Since around 2010 the term 'Anthropocene' has become a buzzword in many academic circles. It names a new, all-encompassing and threatening reality that demands a global and highly sustained response. A concept initially coined and given substance by geoscientists, in recent years numerous social scientists and humanists have sought to understand the causes, effects and implications of the Anthropocene. For researchers across the disciplines, the Anthropocene is breaking down old analytical and topical barriers, even as it reveals sharp differences in cognitive and normative perspectives. Many in the arts have also joined the fray, within and beyond the universities. By the 2030s, the term is likely to have become a societal keyword across the globe. People in all walks of life will come to realise just how profound human impacts on the atmosphere, biosphere, cryosphere, hydrosphere and lithosphere actually are - in large part because various 'epistemic communities' in universities and government agencies will continue to provide robust explanations, arresting evidence and worrying forecasts pertaining to Earth System change. If 'the Anthropocene' signifies anthropogenic impacts on pretty much everything in the physical environment, it also implies the need to also change everything in the ways of thinking and acting that have squeezed the Earth out of its Holocene envelope. And make no mistake: changes to thought and action need to happen now because the future effects of business-as-usual will be very significant indeed for the generations to come, and for non-human species, processes and phenomena. It will also require coordinated action: a few nations acting alone will not suffice. But the 'wickedness' of the Anthropocene problem, the variety of possible means and ends required to 'fix' it, and the inertia caused by those favouring the status quo will make action very slow, very fragmented and highly contested. Where does 'knowledge' feature in this incipient socio-ecological transformation? What kinds of knowledge are required to steer a path forward? Whose knowledge should exert influence in the world to come? What areas of ignorance do we need to shine a light on with new or repurposed knowledge? How can different bodies of knowledge 
be brought into a productive dialogue? And can knowledge be deployed effectively and quickly?

This book seeks to answer these large and very important questions. Traditionally, at least in the West, knowledge meant 'justified true belief'. It was predominantly associated with the natural sciences, the validity of whose knowledge was demonstrated practically through various technologies ('if it works it must be true!'). But, for all their benefits, the knowledge and technologies posed certain risks to human health and the physical environment. In many cases, science and technology became vectors of violence, as with nuclear weapons and the agricultural machinery that remade the ecology of New South Wales, where I currently reside. Despite its supposed autonomy and objectivity, as far back as the 1960s science was shown to be entangled in deeply value-laden social relationships, institutional practices and political agendas cross-cut by struggles for power and influence. As its size and scope increased (in the realms of higher education, government and business), it became ever more contested, throwing-up large ethical questions about who and what benefits and loses in the name of 'scientific progress'. This is not to say that we need to relinquish science and technology in order to create a 'good Anthropocene'. But we do need to ensure that they operate in a wider network of knowledge and practice that will ensure they're governed in ways that include diverse perspectives on how best to rise to the 'Anthropocene challenge'.

In many cases, these perspectives challenge older assumptions about what counts as 'knowledge'. Knowledge is not always about representing 'the truth' because 'justified belief' can relate to ethics, norms and values as much as to facts, objects, or material processes. In addition, 'truth seeking' always occurs in the context of contingent decisions about what's worth knowing and what's not. Knowledge can also be tacit and expressed through learnt practices rather than being made explicit and enduring in research articles, books or manuals. 'Know what' and 'know how' can therefore come in many forms, and be efficacious in very diverse contexts. But the reality of modern life is that certain forms of knowledge have come to dominate thought and action in key domains. For instance, in universities, businesses and state treasuries, particular concepts and methods of economics long ago became normalised globally - one adverse effect of this was the global financial crisis of 2008-9. Looking ahead, can we displace 'hegemonic knowledge' when responding to the Anthropocene challenge? If not, what sort of new hegemonic knowledge do we need to institute? And can we elasticate what counts as knowledge in order to let other voices be heard, so as to mitigate at least some of the epistemic exclusions that hegemony necessarily creates?

Here we face some very significant challenges. On the one hand, geoscientists are sounding the alarm, with many declaring a 'planetary emergency'. 
But on the other hand, our economic and social context is not conducive to constructive dialogue about that emergency. We see deep political divisions within and between the most powerful countries (e.g. the USA, China and Russia); at the time of writing we have a global pandemic that's dominating human affairs to the exclusion of almost everything else; we have a coterie of business leaders who have an awful lot to lose by any switch towards 'green growth', let alone 'de-growth'; we have a fragmented news media landscape, along with ascendant social media, and together they are eroding the basis for shared understanding while fanning the flames of discord; and we have a proliferation of 'alternative facts' and 'fake news' whereby knowledge in its various forms is being substituted by opinion, conviction and wishful thinking. In short, ours is a fractured and very unhappy world at a time when common purpose based on shared values and knowledge is imperative. If the global response to anthropogenic climate change teaches us anything, it's that denial and conflict will precede any meaningful response to the very real threat of a 'bad Anthropocene'. Meanwhile, another kind of response - equally concerning - looms on the horizon: that of science and technology offering us 'emergency solutions' to the Anthropocene challenge that are enacted quickly in 10 or 20 years from now (without proper consultation) and which produce a set of irreversible and undesirable knock-on effects at various spatio-temporal scales.

The chapters of this book cannot provide definitive answers to the profound issues they explore. But they can help us on the journey towards a knowledgeable response to the epic changes human activity has unintentionally instigated. The journey will be incredibly arduous. Unspeakable harm will be inflicted; naïve hope will be trampled under the weight of too many unwelcome events. But the journey may also bring the very best out of people. We desperately need a kinder, more cooperative, more reflective society to emerge from the rubble of neoliberal globalisation. Acute income inequality, the forces of economic competition, the dominance of secular rationality, the prevalence of consumerism, the doctrine of endless growth, the lingering effects of colonialism, religious intolerance, cultural enmity, the hollowing-out of 'public goods', and the persistence of aggressive nationalisms: somehow we need knowledge that can help us tackle all these things while also preventing runaway change to our precious planet. The knowledge will stretch far beyond the realms of science and technology. But for knowledge to matter we also need thought leadership, courageous people willing to speak out, the right institutions to connect all the stakeholders, and the requisite resources to enhance our collective literacy about 'the human planet' that is ours to protect. 